\title{
Investigating the relationship between AI and trust in human-AI collaboration
}

\author{
Ying Bao \\ University of International \\ Business and Economics \\ 2426252877@qq.com
}

\author{
Xusen Cheng \\ Renmin University of \\ China \\ xusen.cheng@ruc.edu.cn
}

\author{
Triparna de Vreede \\ University of South \\ Florida \\ tdevreede@usf.edu
}

\author{
Gert-Jan de Vreede \\ University of South \\ Florida \\ gdevreede@usf.edu
}

\begin{abstract}
With the increasing development of information technology, the implementation of artificial intelligence (AI) has been widespread and has empowered virtual team collaboration by increasing collaboration efficiency and achieving superior collaboration results in recent years. Trust in the process of human-AI interaction has been identified as a challenge for team collaboration in this context. However, little research has investigated the relationship between human-AI interaction and trust. This study proposes a theoretical model of the relationship between human-AI interaction and team members' trust during collaboration processes. We conclude that team members' cognitive and emotional perceptions during the interaction process are associated with their trust towards AI. Moreover, the relationship could also be moderated by the specific AI implementation traits. Our model provides a holistic view of human-AI interaction and its association with team members' trust in the context of team collaboration.
\end{abstract}

\section{Introduction}

The increasing use of advanced information and communication technology (ICT), such as Artificial Intelligence (AI) and big data, has empowered online team collaboration in business. For example, companies such as IBM, e-Bay, and Microsoft organize their many meetings and seminars online, instead of holding traditional face-to-face meetings [1]. In such meetings, according to Bader et al. [2], knowledge-based systems can take on the role of assistant, critic, second opinion, expert consultant, tutor, and automated decision-maker [2]. In the context of team collaboration, the role of AI can also transform from tool to partner [3]: For example, instead of facilitating the collaboration process, AI can also participate in decision making and interact with humans during the collaboration process. This new trend has attracted lots of attention and controversy [4]. On the one hand, AI can provide deeper insights during collaboration process and increase team members' trust and reliance [3]. On the other hand, the trust relationship between human and $\mathrm{AI}$ is volatile. For example, in a survey of US consumers' perception of AI services (e.g., investment advice, medical diagnosis, home services), $41.5 \%$ of participants said they did not trust the services provided by AI, while only $9 \%$ of the participants said they trusted the financial services provided by AI, and only $4 \%$ trusted the employee hiring based on AI [5]. In addition to the role of $\mathrm{AI}$, other $\mathrm{AI}$ implementation traits such as the task-AI fit can also impact team collaboration and trust [6]. AI should fit individuals' preference or collaboration task in the team. As a result, there is a need for a deeper understanding of the antecedents of trust during the human-AI interaction and deriving guidelines for the development and deployment of AI in such a way to facilitate the development of trust.

Existing studies have dealt with several antecedents of trust in traditional research settings, including in the social commerce, team collaboration, and e-government [5][6][7][8]. In addition, trust has also been investigated with respect to several objects of trust, such as trust towards technology [11], team [12], and team leader [13]. Although trust has been shown to be an important issue in the human-AI interaction context, the systematic understanding of trust during human-AI interaction, especially in the team collaboration context, is still limited. In addition, unlike the trust relationship in the traditional team collaboration context, trust in the human-AI interaction context is a broader phenomenon: it involves not only interpersonal trust but also trust in the AI technology. We refer to a person's trust in AI technology as "AI trust". Therefore, we tend to provide a holistic view and a deeper understanding of team members' trust in human-AI collaboration. To this end, we pursue the following research questions in this study:

Research question 1 (RQ1): What are the antecedents of team members' AI trust in the context of human-AI collaboration?

Research question 2 (RQ2): How does specific AI implementation traits associate with the relationship between user perception and $\mathrm{AI}$ trust? 
To answer the above research questions, we first report on a systematic literature review of trust and human-AI interaction research, especially in the team collaboration context. Then we develop a theoretical model of trust in a human-AI collaboration context, where humans communicate or collaborate with a machine teammate.

The remainder of this paper is structured as follows. First, we introduce the research background and literature review on trust, human-AI interaction, and impact of IT adoption. Next, we present the research model and hypotheses. Finally, we conclude with a summary of this research and describe future research.

\section{Literature review}

Trust has been shown to be an important element in the building rapport among people [14]. However, relatively little is known about trust issues related to the adoption of $\mathrm{AI}$ in team collaboration. Therefore, we present relevant literature on IT adoption in team collaboration, trust, and human-AI interaction in this section.

\subsection{Human-AI interaction}

AI has become a key target of technological innovation in business practice [2][13]. AI can be generally defined as "intelligent systems with the ability to think and learn" [16]. In recent years, AI has been implemented widely into various domains and industries, such as mental health care [17], elementary school education [18], workplace [19], and service marketing [20]. The rise of digital innovation has led scholars to increasingly investigate issues regarding human-AI interaction. Studies on human-AI interaction primarily focused on addressing the following basic questions:

- How does the nature of the machine associate with the process of human-AI interaction?

- How does the nature of the human associate with the process of human-AI interaction?
Regarding the above research questions, scholars have conducted studies on human-AI interaction from several facets. From the perspective of the nature of the machine characteristics in human-AI interaction, existing studies investigated the role of humanoid robots' lateral head tilt [21] and gaze turn-taking cues [20] on user perception. Findings indicate that the magnitude of robots' heads tilted and gaze-turn taking cues have significant effects on humans' perception during the interaction. Moreover, existing studies have also adopted the uncanny valley theory [22] to investigate the impact of machine-human similarity on their perception of human-AI interaction. The uncanny valley theory refers to the phenomenon that robots with extremely high human-like looks may lead to users' negative perception during the interaction, even with the feeling of eeriness [21]. Specifically, enriched animated elements of the robots will enhance the negative effect and uncanny valley effect of users [23].

From the perspective of human nature, scholars have investigated the effect of personality traits on human-AI interaction [28][29]. For example, age, gender, personality, cultural background, experience with technology, self-efficacy, subjective norm, and user anxiety have been investigated as important antecedents of user perception [16][26][30]. To be more specific, the perception of people in the interaction process can relate to the interaction comfort [28], discomfort [29], perceived enjoyment [18], perceived trust [14], social presence [27], usefulness and ease of use [18]. For example, studies have indicated that humanoid robots cause greater consumer discomfort, which in turn promotes their compensatory consumption behavior (i.e. consumption to reduce perceived self-threat, for example threats to one's social standing resulting in increased willingness to spend on status-signaling products) [28]. Also, a high level of interaction comfort was shown to be associated with higher users' trust [20]. Table 1 presents a summary of the human-AI interaction literature in recent years.

Table 1. Summary of the human-Al interaction literature

\begin{tabular}{|l|l|l|l|l|}
\hline References & Research context & User perception & $\begin{array}{l}\text { Interaction } \\
\text { outcomes }\end{array}$ & Findings \\
\hline$[26]$ & $\begin{array}{l}\text { Automated } \\
\text { decision making } \\
\text { based on AI }\end{array}$ & $\begin{array}{l}\text { Privacy concerns, self- } \\
\text { efficacy, age, gender, } \\
\text { decision-making type, } \\
\text { AI role, knowledge } \\
\text { level }\end{array}$ & $\begin{array}{l}\text { Perceived } \\
\text { justice, } \\
\text { perceived } \\
\text { usefulness, } \\
\text { perceived risk }\end{array}$ & $\begin{array}{l}\text { Knowledge level of AI users has } \\
\text { a significant positive effect on } \\
\text { their perceived AI usefulness. } \\
\text { Self-efficacy positively affects } \\
\text { perceived fairness, perceived } \\
\text { usefulness and negatively affects } \\
\text { perceived risk. Age has a } \\
\text { negative impact on users' }\end{array}$ \\
& & & & \\
\hline
\end{tabular}




\begin{tabular}{|c|c|c|c|c|}
\hline & & & & $\begin{array}{l}\text { perceived fairness and } \\
\text { usefulness. Females see the AI as } \\
\text { less useful that males. }\end{array}$ \\
\hline [29] & $\begin{array}{l}\text { Algorithmic } \\
\text { recommendation } \\
\text { decision }\end{array}$ & $\begin{array}{l}\text { Task objectivity, trust, } \\
\text { algorithm's affective } \\
\text { human likeness, } \\
\text { discomfort, } \\
\text { effectiveness }\end{array}$ & $\begin{array}{l}\text { Reliance on } \\
\text { algorithm }\end{array}$ & $\begin{array}{l}\text { Trust in algorithm is negatively } \\
\text { related to the subjectivity of the } \\
\text { task. The negative effect will be } \\
\text { eliminated when the level of } \\
\text { algorithms' affective human- } \\
\text { likeness is high. Effectiveness of } \\
\text { the algorithm plays a more } \\
\text { important role than perceived } \\
\text { discomfort in determining users' } \\
\text { reliance on algorithm. }\end{array}$ \\
\hline$[23]$ & $\begin{array}{l}\text { Human-chatbot } \\
\text { interaction }\end{array}$ & $\begin{array}{l}\text { Electromyography, } \\
\text { respirometer, } \\
\text { electrocardiograph, } \\
\text { and electrodermal } \\
\text { activity }\end{array}$ & $\begin{array}{l}\text { Attitude towards } \\
\text { collaborate with } \\
\text { chatbot }\end{array}$ & $\begin{array}{l}\text { Comparing with a more complex } \\
\text { chatbot, humans experience } \\
\text { fewer fear effects and fewer } \\
\text { negative effects when interacting } \\
\text { with a simpler text bot. Simple } \\
\text { chatbots elicit relatively few } \\
\text { psychophysiological responses. }\end{array}$ \\
\hline$[17]$ & $\begin{array}{l}\text { Human-robot } \\
\text { interactions in } \\
\text { mental health care }\end{array}$ & Interact with robot & $\begin{array}{l}\text { Affective states, } \\
\text { physiological } \\
\text { arousal, } \\
\text { cognitive } \\
\text { performances } \\
\text { and workload }\end{array}$ & $\begin{array}{l}\text { There is no difference in humans' } \\
\text { emotional processes between } \\
\text { human-human interaction and } \\
\text { human-robot interaction. From } \\
\text { the perspective of non-verbal } \\
\text { behavior, users spent more time } \\
\text { eye-contacting with the robot } \\
\text { than human examiner. }\end{array}$ \\
\hline [18] & $\begin{array}{l}\text { Humanoid robot } \\
\text { in preschool and } \\
\text { elementary school }\end{array}$ & $\begin{array}{l}\text { Anxiety, attitude, } \\
\text { perceived sociability, } \\
\text { enjoyment, } \\
\text { adaptability }\end{array}$ & Intention to use & $\begin{array}{l}\text { Anxiety and perceived } \\
\text { adaptability positively impact } \\
\text { users' perceived usefulness, and } \\
\text { thus, increase users' intention to } \\
\text { use the humanoid robot. }\end{array}$ \\
\hline [27] & $\begin{array}{l}\text { Acceptance of } \\
\text { assistive social } \\
\text { agents by the } \\
\text { elderly user }\end{array}$ & $\begin{array}{l}\text { Perceived adaptability, } \\
\text { anxiety, social } \\
\text { presence, perceived } \\
\text { sociability, ease of use, } \\
\text { usefulness, enjoyment, } \\
\text { trust }\end{array}$ & Intention to use & $\begin{array}{l}\text { Perceived anxiety and } \\
\text { adaptability will increase } \\
\text { perceived usefulness. Perceived } \\
\text { sociability increases users' } \\
\text { perceived enjoyment. Users' } \\
\text { attitude toward the technology } \\
\text { and perceived usefulness will } \\
\text { increase their intention to use the } \\
\text { technology. }\end{array}$ \\
\hline$[30]$ & $\begin{array}{l}\text { Human- } \\
\text { automation } \\
\text { interaction }\end{array}$ & $\begin{array}{l}\text { Age, personality traits, } \\
\text { gender, culture, } \\
\text { previous experience }\end{array}$ & $\begin{array}{l}\text { Trust towards } \\
\text { automation }\end{array}$ & $\begin{array}{l}\text { Provides a systematical lens of } \\
\text { human-automation trust (learned } \\
\text { trust, dispositional trust and } \\
\text { situational trust). }\end{array}$ \\
\hline [19] & $\begin{array}{l}\text { Human-AI } \\
\text { symbiosis in } \\
\text { decision making }\end{array}$ & $\begin{array}{l}\text { Uncertainty, } \\
\text { complexity, and } \\
\text { equivocality of the } \\
\text { task }\end{array}$ & $\begin{array}{l}\text { Intelligence } \\
\text { augmentation }\end{array}$ & $\begin{array}{l}\text { AI has stronger computational } \\
\text { information processing capacity } \\
\text { and analytical methods, which } \\
\text { can extend human cognition } \\
\text { when dealing with complex } \\
\text { problems, while humans can still } \\
\text { provide more comprehensive and } \\
\text { intuitive methods when dealing }\end{array}$ \\
\hline
\end{tabular}




\begin{tabular}{|c|c|c|c|c|}
\hline & & & & $\begin{array}{l}\text { with uncertain and ambiguous } \\
\text { decisions. }\end{array}$ \\
\hline [28] & $\begin{array}{l}\text { Humanoid robots } \\
\text { in service } \\
\text { experiences }\end{array}$ & Consumer discomfort & $\begin{array}{l}\text { Compensatory } \\
\text { purchase } \\
\text { behavior }\end{array}$ & $\begin{array}{l}\text { Humanoid robots cause greater } \\
\text { consumer discomfort, which in } \\
\text { turn promotes their } \\
\text { compensatory consumption } \\
\text { behavior. }\end{array}$ \\
\hline [21] & $\begin{array}{l}\text { Human responses } \\
\text { to android and } \\
\text { humanoid robots }\end{array}$ & Lateral head tilt & $\begin{array}{l}\text { Perceived } \\
\text { warmth, } \\
\text { eeriness, } \\
\text { attractiveness, } \\
\text { and dominance } \\
\end{array}$ & $\begin{array}{l}\text { Robots with tilted heads scored } \\
\text { higher on users' perceived } \\
\text { similarity, likability, and } \\
\text { excitement than those with } \\
\text { upright heads. }\end{array}$ \\
\hline [31] & $\begin{array}{l}\text { Interaction with } \\
\text { social robots in } \\
\text { the workplace }\end{array}$ & $\begin{array}{l}\text { Negative and positive } \\
\text { anticipated emotions, } \\
\text { perceived behavioral } \\
\text { control, subjective } \\
\text { norm, competence }\end{array}$ & $\begin{array}{l}\text { Intention to } \\
\text { work with social } \\
\text { robots }\end{array}$ & $\begin{array}{l}\text { Perceived warmth of robots will } \\
\text { increase users' attitude, positive } \\
\text { emotions, perceived behavior } \\
\text { control, subjective norm and } \\
\text { decrease users' negative } \\
\text { emotions. Moreover, subjective } \\
\text { norm, positive and negative } \\
\text { emotions will significantly } \\
\text { impact the behavior desire and } \\
\text { intention to work with the robot. }\end{array}$ \\
\hline [14] & $\begin{array}{l}\text { Interaction with } \\
\text { collaborative } \\
\text { Robot in the } \\
\text { workplace }\end{array}$ & $\begin{array}{l}\text { Perception of } \\
\text { interaction }\end{array}$ & $\begin{array}{l}\text { Rapport building } \\
\text { hindering } \\
\text { bahavior }\end{array}$ & $\begin{array}{l}\text { Individuals have a positive } \\
\text { attitude toward building close } \\
\text { relationships with their robot } \\
\text { teammates, such as thanking and } \\
\text { praising the robot. }\end{array}$ \\
\hline [32] & $\begin{array}{l}\text { Interaction with } \\
\text { service-providing } \\
\text { humanoid robots }\end{array}$ & $\begin{array}{l}\text { Automated social } \\
\text { presence, perceptions } \\
\text { of psychological } \\
\text { ownership }\end{array}$ & $\begin{array}{l}\text { Service and } \\
\text { customer } \\
\text { outcomes }\end{array}$ & $\begin{array}{l}\text { Social cognition and } \\
\text { psychlogical contract act as } \\
\text { mediators of the relationship } \\
\text { between human social presence } \\
\text { and service and cutomer } \\
\text { outcomes. }\end{array}$ \\
\hline [20] & $\begin{array}{l}\text { Humanoid robots } \\
\text { in services } \\
\text { marketing }\end{array}$ & $\begin{array}{l}\text { Consumers' perceived } \\
\text { anthropomorphism, } \\
\text { comfort }\end{array}$ & $\begin{array}{l}\text { Trust, } \\
\text { enjoyment, } \\
\text { intention to use }\end{array}$ & $\begin{array}{l}\text { Perceived interaction comfort } \\
\text { moderates the relationship } \\
\text { between gaze-turn taking cues } \\
\text { and anthropomorphism, and thus, } \\
\text { leads to higher level of trust, } \\
\text { enjoyment and intention to use. }\end{array}$ \\
\hline [33] & $\begin{array}{l}\text { Interaction with } \\
\text { service robots }\end{array}$ & $\begin{array}{l}\text { Perceived ease of use, } \\
\text { usefulness, suejective } \\
\text { social norm, } \\
\text { interactivity, social } \\
\text { presence, trust, rapport }\end{array}$ & $\begin{array}{l}\text { Acceptancce and } \\
\text { actual use of } \\
\text { service robots }\end{array}$ & $\begin{array}{l}\text { This paper provides the } \\
\text { definition of a service robot, } \\
\text { describes its key attributes, and } \\
\text { compares it with the services of } \\
\text { front-line employees. It } \\
\text { concludes that robots and } \\
\text { humans are suitable for leading } \\
\text { tasks respectively. Secondly, it } \\
\text { investigates consumers' cognitive } \\
\text { beliefs and behaviors towards } \\
\text { service robots, and proposes a } \\
\text { service robot acceptance model. }\end{array}$ \\
\hline
\end{tabular}




\subsection{IT implementation traits in team collaboration}

In human-AI interaction, both humans' perception and AI implementation characteristics play an important role in the interaction results. Previous studies have investigated the impact of IT implementation on team performance or team collaboration. Existing studies have investigated several factors that affect team members' perceptions of IT artifacts. For example, perceived interaction comfort with a robot was found to moderate the relationship between robots' gaze turntaking cues and humans' perceived anthropomorphism [20]. Computer playfulness can predict users' acceptance of technology [34]. Perceived flexibility of the IT infrastructure was found to have an indirect effect on performance in the context of mergers and acquisitions [35]. Additionally, task-technology fit has also been shown to be an important trait of IT implementation. Liu et al. [36] argued that the IT elements should fit the individuals, tasks and even desired user-system interactions [36]. In this study, we mainly focus on two types of AI implementation characteristics in the team collaboration context: task$\mathrm{AI}$ fit and the role of AI.

As mentioned earlier, knowledge-based systems can act as the role of assistant, critic, second opinion, expert consultant, tutor, and automated decision-maker [2]. Therefore, the role that AI plays in team collaboration can also impact users' perception of the human-AI interaction process [26]. And in the AI-facilitated team collaboration context, the role of AI can also be an important element in determining the team members' perceptions. For example, team members' perceptions will differ when AI acts as a facilitator, team leader, or team member in the collaboration [3]. In our research, we mainly focus on the following two roles of AI in the team collaboration: facilitator and team member.

From the perspective of task-AI fit, we synthesized previous studies on systems design in team collaboration and technology fit into a task-AI fit framework in this research context [42][43]. Existing studies provide an extension of system design in the team collaboration context. In the traditional team collaboration context, scholars have been developing and applying the approach to assist group collaboration [39]. For example, the collaboration engineering (CE) approach has been used to package technology and usage documentation to design a collaborative process [40]. In the human-AI team collaboration context, additional requirements have to be taken into consideration when using the $\mathrm{CE}$ approach to design effective team collaboration. For example, the selected AI to serve as a facilitator should fit the collaboration tasks while the AI acting as a team member should be fit the humans' individual preferences [3].

\subsection{Trust in human-AI interaction}

Among the various antecedents of effective humanAI interaction, the trust relationship between human and machine has been found to be an important issue and received much attention. According to technology transition model (TTM), the team chooses to embrace or abandon collaboration technology due to their perceived frequency of the net value, magnitude of net value and perceived value of technology transition [41][42][43]. As such, trust can be regarded as an important instantiation of the magnitude of value in the TTM. A low level of trust will reduce users' perceived magnitude of value, as thus, leading the possibility to technology abandonment. Therefore, trust in the human$\mathrm{AI}$ interaction is also essential in this research context.

Trust has also been investigated in many other research contexts. In the context of service marketing, trust has been identified as an important antecedent of consumers' use behavior [33]. In the context of assistive social agent technology, Heerink et al. [27] investigated the relationship between older adults' trust and their acceptance of assistant technology [27]. Results indicate that a high level of trust will lead to users' acceptance intention and behavior. In the team collaboration context, team trust can, for example, increase team effectiveness [44], emergent use intention [45]. The influence of trust/distrust has also been evaluated from a longitudinal perspective [8]. Findings indicate that trust varies from the initial collaboration stage to the final stage. Seeber et al. [3] has also considered trust and argued that the objects of trust in this context can include machine teammates, intelligence algorithms and their recommendations [3]. In this research, we mainly focus on humans' trust with AI as different roles.

Regarding the antecedents of trust, existing research on the antecedents of trust can be divided into two perspectives: cognitive perspective and emotional perspective [51] [52]. Specifically, cognition-based antecedents mainly refer to computational or rational characteristics, including factors related to the trustworthiness of individuals' perception of others/organizations. Emotion-based antecedents are mainly based on the interaction between individuals and mutual social relationships [12]. In order to have a deeper understanding of the trust antecedents between human-AI interaction, we will also focus on humans' perception from the above two perspectives. 


\section{Research model and hypotheses}

According to the literature review of trust, human$\mathrm{AI}$ interaction and IT implementation traits, we propose the theoretical model in Figure 1. Specifically, the research model provides a holistic view of the effects of team members' perception of the human-AI interaction on their trust. According to McAllister (1995), we investigate the team members' perception in the team member-AI interaction from two perspectives: cognitive perspective and emotional perspective [46]. Previous research on TAM (Technology Acceptance Model) [48], TTM (Technology Transition Model) [41], and Roger's stage model of innovation [49] also summarized several cognitive and emotional dimensions that affect the effectiveness and adoption intention of IT [42]. Antecedents in this research model were derived from the existing studies on IT adoption, trust, and human-AI interaction. The moderating role of AI implementation traits is also considered in this research model.

From the cognitive perspective, computational or rational characteristics will affect individuals' cognitive-based trust. In the context of human-AI collaboration, interaction complexity and coordination costs are included in our theoretical model as cognitive foundations of trust in AI. Interaction complexity in this research refers to the degree to which the AI facilitator or team member is perceived to be difficult to interact with. Perceived high level of interaction complexity of the team members will lead to their doubt on the effectiveness of AI. On the other hand, no matter whether the $\mathrm{AI}$ acts as a facilitator or as a team member, coordination between team members and $\mathrm{AI}$ is inevitable. For instance, teams coordinate to process the timing of workflow [44]. As a result, the high level of interaction coordination cost will also decrease individuals' trust level. Thus, we propose the following hypotheses:

H1a: Interaction complexity has a negative relationship with team members' trust towards AI.

H1b: Interaction coordination cost has a negative relationship with team members' trust towards AI.

From the emotional perspective, emotional and psychological elements during the human-AI interaction process also play an essential role in determining humans' trust. In this research context, we focus on interaction comfort and interaction enjoyment of individuals as they relate to their trust in AI. Specifically, interaction comfort refers to an emotional state. When feeling discomfort during the interaction with AI, humans are expected to take uncertainty reduction strategies to increase AI's predictability [20]. We propose that perceived high comfort during the interaction process will decrease the uncertainty and increase team members' trust in AI. Yet, the implementation of $\mathrm{AI}$ in the team collaboration context can be regarded as a technology innovation. As is discussed by Hess et al [50], technology playfulness will affect users' social presence, as thus, increasing their trust in the recommendation agents. As a result, team members' perceived interaction enjoyment can also impact their trust in the AI. Therefore, the following hypotheses are proposed:

H2a: Interaction comfort has a positive relationship with team members' trust towards AI.

H2b: Interaction enjoyment has a positive relationship with team members' trust towards AI.

Specific traits of AI implementation are also thought to be important in the interaction process. Accordingly, we include two IT-specific traits in our theoretical model.

In the traditional team collaboration context, the team's task has been shown to account for large variation in the interaction [6]. Moreover, tasktechnology fit is also a principle for the effective technology implementation in collaboration settings [6]. Specifically, task-technology fit can be defined as the ideal alignment of tasks and technology. In the team collaboration context, team members are assigned in a group to address a task together with AI acting as a facilitator or team member. A high level of task-AI fit will enhance or release the effects of individuals' perception of their trust towards AI. For example, when experiencing high task/AI fit, individuals will be more tolerant of the interaction complexity, as thus, decreasing the negative correlations between the interaction complexity and trust. Thus, the following hypotheses are proposed:

H3a: Task-AI fit negatively moderates the relationship between interaction complexity and trust towards AI.

H3b: Task-AI fit negatively moderates the relationship between interaction coordination cost and trust towards AI.

H3c: Task-AI fit positively moderates the relationship between interaction comfort and trust towards AI. 
H3d: Task-AI fit positively moderates the relationship between interaction enjoyment and trust towards AI.

In addition to task-AI fit, the role that AI plays in the team collaboration process is also expected to correlates with the relationship between team members' perception and trust. According to existing studies [2][3], we focus on the role of AI as a facilitator and team member in this research. For example, in the traditional team collaboration context, the facilitators were usually professional and hired internally or externally [42]. These professional facilitators are normally expected to be efficient and effective in the facilitation support. Therefore, when AI acts as a facilitator in the team collaboration, team members will put more emphasis on the effectiveness and coordination ability of the facilitator. As a result, we propose that team members' cognitive perception has a significant positive relationship with the role of the AI. Therefore, the effects of interaction complexity and coordination cost on trust will be different regarding the different roles of AI. Likewise, when the AI acts as a team member, the interaction between human and the
AI "teammate" will be more frequent in the discussion or decision-making process. Therefore, team members will emphasize their emotional perception during the interaction process. Consequently, the effects of interaction comfort and enjoyment on trust will be associated with the different roles of AI. Therefore, the following hypotheses are proposed:

H4a: The role of AI as a facilitator negatively moderates the relationship between interaction complexity and trust towards AI.

H4b: The role of AI as a facilitator negatively moderates the relationship between interaction coordination cost and trust towards AI.

H4c: The role of $A I$ as a facilitator negatively moderates the relationship between interaction comfort and trust towards AI.

H4d: The role of AI as a facilitator negatively moderates the relationship between interaction enjoyment and trust towards AI.

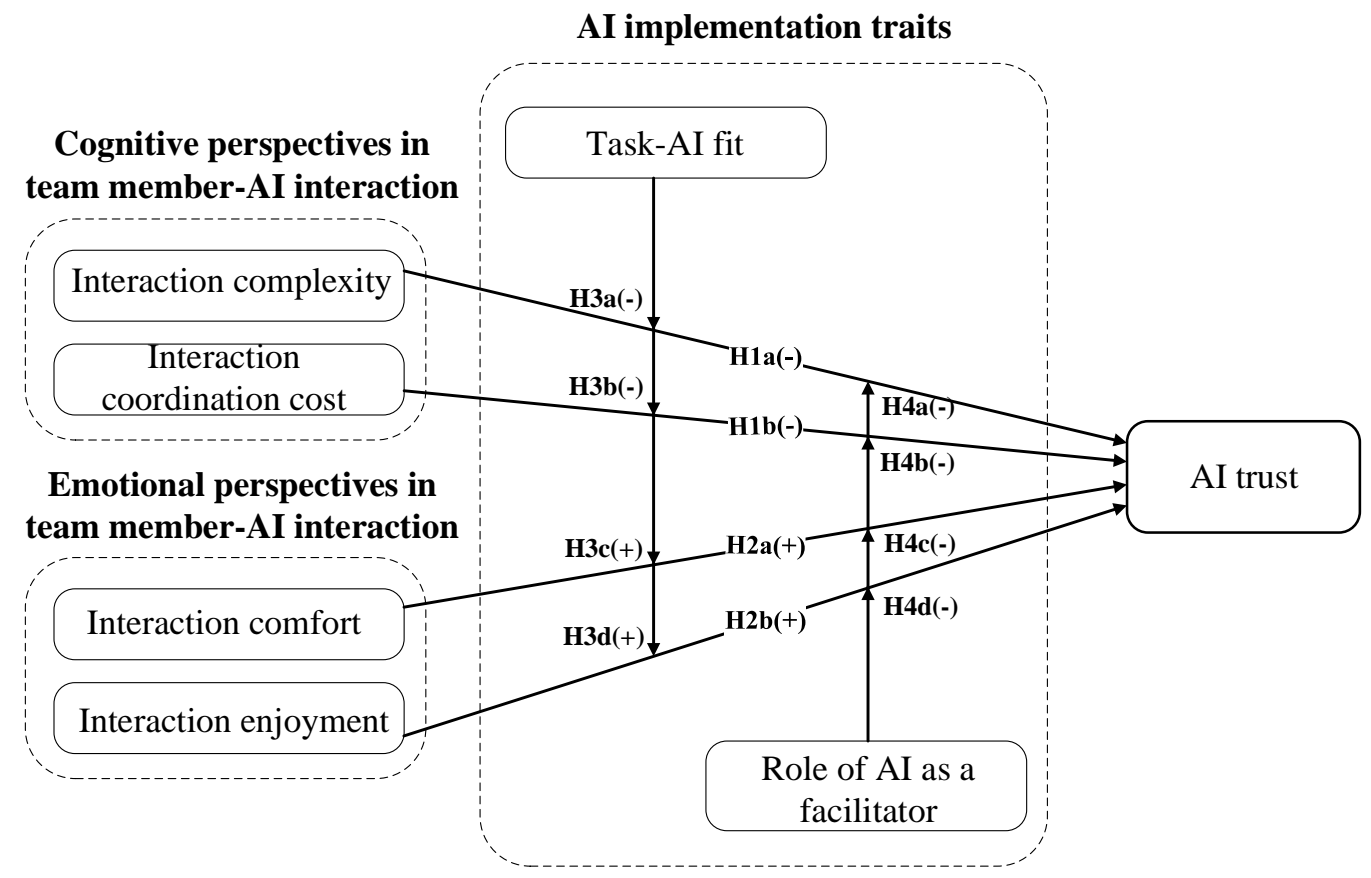

Figure 1. Research model

\section{Conclusion and future research}

\subsection{Conclusion}

Although the impact of IT implementation in different context has been investigated from several facets, the prevalence of human-AI interaction has presented new management and practical issues. The effects of AI implementation on trust has been shown 
to be essential in the human-AI interaction field, however, a systematic investigation into trust or collaboration performance-related issues is still limited. Inspired by studies on human-AI interaction and IT adoption, we notice the necessity and research gap in the relationship between human and AI in the collaboration context, especially considering the specific features of AI artifacts. For example, when adopting an AI program to recommend the team collaboration process automatically, cognitive and emotional perceptions of team members are expected to lead to a different evaluation of the AI artifacts, and thus, lead to diversity outcomes of collaboration performance and trust. Specifically, we conclude that the specific AI implementation traits in the team collaboration context may include the role of AI (facilitator or team member) and AI-task fit. Take the role of AI as an example, when AI plays the role as a team facilitator or team member in the collaboration, the relationship between the perceptions and AI evaluation will be different. The above discussion is also consistent with previous studies that argue that trust and the role of AI in team collaboration need to be addressed [3]. The above AI implementation traits may moderate the relationship between perceptions of human-AI interaction and team members' trust.

\subsection{Future work}

As this study presents a theoretical model, there are still limitations in the current version of this study. For example, the theoretical model and observed relationships between each construct are mainly based on the human-AI collaborations context in this study. New findings can be discovered in the future research under other conditions. Moreover, this research model only takes the moderating effects of AI implementation traits into consideration. In business practice and team collaboration, both team member personality traits and team traits will impact team members' perception during the human-AI interaction. By integrating insights from previous studies, more characteristics could be taken into consideration when designing AI systems to assist team collaboration in future practice and research. In future research, we will conduct a lab experiment and test the hypotheses proposed in this theoretical model empirically. Specifically, participants of the experiment will be randomly assigned to two groups, one with the AI acting as a facilitator, the other with the AI acting as a team member in the team collaboration. After completing the team collaboration process, participants will be asked to fill in a survey, involving their perceptions of the interaction with $\mathrm{AI}$, trust towards AI, and trust towards the team. Results of the data analysis will provide empirical evidence of the theoretical model. Moreover, we also plan to collect interview data to supplement the results for further investigation. More antecedents and specific AI implementation traits need to be further investigated in the future research.

\section{Acknowledgement}

The authors would like to thank National Natural Science Foundation of China (Grant No.71571045) for providing funding for part of this research. Xusen Cheng is the corresponding author.

\section{References}

[1] G.J. de Vreede, M. Limayem, and I. Boughzala, "Introduction to the working and gaming in $3 \mathrm{~d}$ virtual environments minitrack", Proceedings of the 46th Hawaii International Conference on System Sciences, 2013, pp. 843.

[2] J. Bader, J. Edwards, C. Harris-Jones, and D. Hannaford, "Practical engineering of knowledge-based systems", Information and Software Technology, 30(5), 1988, pp. 266-277.

[3] I. Seeber, E. Bittner, R.O. Briggs, T. de Vreede, G.J. de Vreede, A. Elkins, R. Maier, A.B. Merz, S. OesteReiß, N. Randrup, and G. Schwabe, "Machines as teammates: A research agenda on AI in team collaboration", Information and Management, 57(2), 2020, pp. 103174.

[4] Y. Duan, J.S. Edwards, and Y.K. Dwivedi, "Artificial intelligence for decision making in the era of Big Data - evolution, challenges and research agenda", International Journal of Information Management, 48, 2019, pp. 63-71.

[5] T.H. Davenport, “Can we solve AI's 'trust problem'?", MIT Sloan Management Review, 60(2), 2019, pp. $18-19$.

[6] I. Zigurs, and B.K. Buckland, "A theory of task/technology fit and group support systems effectiveness", MIS Quarterly, 22(3), 1998, pp.313-334.

[7] R. Filieri, S. Alguezaui, and F. McLeay, "Why do travelers trust TripAdvisor? Antecedents of trust towards consumer-generated media and its influence on recommendation adoption and word of mouth", Tourism Management, 51, 2015, pp. 174185.

[8] X. Cheng, S. Fu, and D. Druckenmiller, "Trust development in globally distributed collaboration: A case of U.S. and Chinese mixed teams", Journal of Management Information Systems, 33(4), 2016, pp. 978-1007.

[9] X. Cheng, G. Yin, A. Azadegan, and G. Kolfschoten, "Trust evolvement in hybrid team collaboration: A longitudinal case study", Group Decision and Negotiation, 25(2), 2016, pp. 267-288. 
[10] X. Cheng, S. Fu, and G.J. de Vreede, "Understanding trust influencing factors in social media communication: A qualitative study", International Journal of Information Management, 37(2), 2017, pp. 25-35.

[11] I. Gaudiello, E. Zibetti, S. Lefort, M. Chetouani, and S. Ivaldi, "Trust as indicator of robot functional and social acceptance. An experimental study on user conformation to iCub answers", Computers in Human Behavior, 61, 2016, pp. 633-655.

[12] M. Dayan and C.A. Di Benedetto, "The impact of structural and contextual factors on trust formation in product development teams", Industrial Marketing Management, 39(4), 2010, pp. 691-703.

[13] K.T. Dirks and D.L. Ferrin, "Trust in leadership: Metaanalytic findings and implications for research and practice", Journal of Applied Psychology, 87(4), 2002, pp. 611-628.

[14] S.H. Seo, K. Griffin, J.E. Young, A. Bunt, S. Prentice, and V. Loureiro-Rodríguez, "Investigating people's rapport building and hindering behaviors when working with a collaborative robot", International Journal of Social Robotics, 10(1), 2018, pp. 147-161.

[15] S. Robinson, C. Orsingher, L. Alkire, A. De Keyser, M. Giebelhausen, K.N. Papamichail, P. Shams, and M.S. Temerak, "Frontline encounters of the AI kind: An evolved service encounter framework", Journal of Business Research, 116, 2019, pp. 1-11.

[16] G. Brewka, "Artificial intelligence-a modern approach by Stuart Russell and Peter Norvig, Prentice Hall. Series in Artificial Intelligence, Englewood Cliffs, NJ," The Knowledge Engineering Review, 11(1), 1996, pp. 78-79.

[17] L. Desideri, C. Ottaviani, M. Malavasi, R. di Marzio, and P. Bonifacci, "Emotional processes in humanrobot interaction during brief cognitive testing", Computers in Human Behavior, 90, 2019, pp. 331342.

[18] M. Fridin and M. Belokopytov, “Acceptance of socially assistive humanoid robot by preschool and elementary school teachers", Computers in Human Behavior, 33, 2014, pp. 23-31.

[19] M. H. Jarrahi, "Artificial intelligence and the future of work: Human-AI symbiosis in organizational decision making”, Business Horizons, 61(4), 2018, pp. 577-586.

[20] M.M. E. van Pinxteren, R.W.H. Wetzels, J. Rüger, M. Pluymaekers, and M. Wetzels, "Trust in humanoid robots: implications for services marketing", Journal of Services Marketing, 33(4), 2019, pp. 507-518.

[21] M. Mara and M. Appel, "Effects of lateral head tilt on user perceptions of humanoid and android robots", Computers in Human Behavior, 44, 2015, pp. 326334.

[22] M. Mori, "The uncanny valley: The original essay by Masahiro Mori", IEEE Robotics \& Automation Magazine, 12, 2012, pp. 1-6.

[23] L. Ciechanowski, A. Przegalinska, M. Magnuski, and P. Gloor, "In the shades of the uncanny valley: An experimental study of human-chatbot interaction", Future Generation Computer Systems, 92, 2019, pp. $539-548$

[24] T.H. Davenport and R. Ronanki, "Artificial intelligence for the real world", Harvard Business Review, 96(1), 2018, pp. 108-116.

[25] S. Jessup, A. Gibson, A. Capiola, G. Alarcon, and M. Borders, "Investigating the effect of trust manipulations on affect over time in human-human versus human-robot interactions", Proceedings of the 53rd Hawaii International Conference on System Sciences, 2020.

[26] T. Araujo, N. Helberger, S. Kruikemeier, and C.H. de Vreese, "In AI we trust? Perceptions about automated decision-making by artificial intelligence", AI and Society, 2020, pp. 1-13.

[27] M. Heerink, B. Kröse, V. Evers, and B. Wielinga, "Assessing acceptance of assistive social agent technology by older adults: The almere model", International Journal of Social Robotics, 2(4), 2010, pp. 361-375.

[28] M. Mende, M.L. Scott, J. van Doorn, D. Grewal, and I. Shanks, "Service robots rising: How humanoid robots influence service experiences and elicit compensatory consumer responses", Journal of Marketing Research, 56(4), 2019, pp. 535-556.

[29] N. Castelo, M.W. Bos, and D.R. Lehmann, "Taskdependent algorithm aversion", Journal of Marketing Research, 56(5), 2019, pp. 809-825.

[30] K.A. Hoff and M. Bashir, "Trust in automation: Integrating empirical evidence on factors that influence trust", Human Factors, 57(3), 2015, pp. 407-434.

[31] N. Piçarra and J.C. Giger, "Predicting intention to work with social robots at anticipation stage: Assessing the role of behavioral desire and anticipated emotions", Computers in Human Behavior, 86, 2018, pp. 129-146.

[32] J. Van Doorn, M. Mende, S.M. Noble, J. Hulland, A.L. Ostrom, D. Grewal, and J.A. Petersen, "Domo Arigato Mr. Roboto: emergence of automated social presence in organizational frontlines and customers' service experiences", Journal of Service Research, 20(1), 2017, pp. 43-58.

[33] J. Wirtz, P.G. Patterson, W.H. Kunz, T. Gruber, V.N. Lu, S. Paluch, and A. Martins, "Brave new world: service robots in the frontline", Journal of Service Management, 29(5), 2018, pp. 907-931.

[34] J.B. Thatcher, R.T. Wright, H. Sun, T.J. Zagenczyk, and R. Klein, "Mindfulness in information technology use: Definitions, distinctions, and a new measure", MIS Quarterly, 42(3), 2018, pp. 831-847.

[35] J. Benitez, G. Ray, and J. Henseler, "Impact of information technology infrastructure flexibility on mergers and acquisitions", MIS Quarterly, 42(1), 2018, pp. 25-43.

[36] D. Liu, R. Santhanam, and J. Webster, "Toward meaningful engagement: A framework for design and research of gamified information systems", MIS Quarterly, 41(4), 2017, pp. 1011-1034. 
[37] T.L. James, L. Wallace, and J.K. Deane, "Using organismic integration theory to explore the associations between users' exercise motivations and fitness technology feature set use", MIS Quarterly, 43(1), 2019, pp. 287-312.

[38] A. M. Curtis, A.R. Dennis, and K.O. McNamara, "From monologue to dialogue: Performative objects to promote collective mindfulness in computermediated team discussions”, MIS Quarterly, 41(2), 2017, pp. 559-581.

[39] X. Cheng, Y. Li, J. Sun, and J. Huang, “Application of a novel collaboration engineering method for learning design: A case study", British Journal of Educational Technology, 47(4), 2016, pp. 803-818.

[40] G.L. Kolfschoten, R.O. Briggs, G.J. de Vreede, P.H.M. Jacobs, and J.H. Appelman, "A conceptual foundation of the thinkLet concept for Collaboration Engineering", International Journal of Human Computer Studies, 64(7), 2006, pp. 611621.

[41] R. O. Briggs, M. Adkins, J.K. Mittleman, S. Miller, and J.F. Nunamker Jr, "A technology transition model derived from field investigation of GSS use aboard the U.S.S. CORONADO", Journal of Management Information Systems, 15(3), 1999, pp.151-195.

[42] R.O. Briggs, G.J. de Vreede, and J.F. Nunamaker, "Collaboration engineering with thinklets to pursue sustained success with group support systems", Journal of Management Information Systems, 19(4), 2003, pp. 31-64.

[43] T. de Vreede, G.J. de Vreede, G. Ashley, and R. Reiterpalmon, "Exploring the effects of personality on collaboration technology transition", Proceedings of the 45th Hawaii International Conference on System Sciences, 2012.

[44] C. Breuer, J. Hüffmeier, and G. Hertel, "Does trust matter more in virtual teams? A meta-analysis of trust and team effectiveness considering virtuality and documentation as moderators", Journal of Applied Psychology, 101(8), 2016, pp. 1151-1177.

[45] S.C. Srivastava and S. Chandra, "Social presence in virtual world collaboration: An uncertainty reduction perspective using a mixed methods approach", MIS Quarterly, 42(3), 2018, pp. 779803.

[46] D.J. McAllister, "Affect- and cognition-based trust as foundations for interpersonal cooperation in organizations", Academy of Management Journal, 38(1), 1995 pp. 24-59.

[47] L. Weber and C.W. Bauman, "The cognitive and behavioral impact of promotion and prevention contracts on trust in repeated exchanges", Academy of Management Journal, 62(2), 2019, pp. 361-382.

[48] F. D. Davis, "A technology acceptance model for empirically testing new end-user information systems: Theory and results", Management, 1985.

[49] E.M. Rogers, Diffusion of Innovations, Fourth Edition, 1995.

[50] T. Hess, M. Fuller, and D. Campbell, "Designing interfaces with social presence: Using vividness and extraversion to create social recommendation agents", Journal of the Association for Information Systems, 10(12), 2009, pp.1. 